\title{
Organosulfates - A New Component of Humic-Like Substances in Atmospheric Aerosols?
}

\author{
FERNANDO ROMERO and MICHAEL OEHME \\ Organic Analytical Chemistry, University of Basel, Neuhausstrasse 31, CH-4057 Basel, \\ Switzerland,e-mail: michael.oehme@ unibas.ch
}

(Received: 9 November 2004; accepted: 4 July 2005)

\begin{abstract}
Ion trap mass spectrometry (ITMS) was used to obtain further qualitative information about the chemical composition of humic-like substances (HULIS) in atmospheric particulate matter. Particles $\leq 10 \mu \mathrm{m}\left(\mathrm{PM}_{10}\right)$ were collected on quartz fiber filters for $24 \mathrm{~h}$ in the region of Basel (Switzerland) and extracted with water. HULIS were separated from inorganic salts by size exclusion chromatography (SEC) and detected by electrospray ionization in the negative ion mode (ESI $(-)$ ). Series of consecutive fragment ion spectra $\left(\mathrm{MS}^{\mathrm{n}}\right)$ were recorded by ITMS. Full scan mass spectra of the extracts showed a mass distribution pattern characteristic for HULIS. Different molecular ions were selected from this pattern for further fragmentations. Among them the molecular ion $m / z 299$ was considered as representative and intensively studied. Many $\mathrm{MS}^{2}$ and $\mathrm{MS}^{3}$ fragment spectra contained a fragment $m / z 97$ and a neutral loss of $80 \mathrm{u}$. Time-of-flight (TOF) MS and deuterium exchange experiments identified $m / z, 97$ as hydrogen sulfate. $\mathrm{MS}^{2}$ and $\mathrm{MS}^{3}$ fragment spectra supported the existence of sulfate covalently bound to HULIS. The fragmentation behavior of sulfated HULIS could be confirmed by model compounds.
\end{abstract}

Key words: atmospheric aerosols, CCN, electrospray, HULIS, ion trap mass spectrometry

\section{Introduction}

Particulate matter in the atmosphere has an important influence on atmospheric processes and on our climate. Atmospheric aerosols have a direct effect on solar radiation mainly due to absorption and scattering (Brimblecombe, 1996; Seinfeld and Pandis, 1998; Jacobson et al., 2000). They can cause a warming or cooling effect depending on size, optical properties, chemical composition and abundance. Currently, a global cooling effect of ca. -0.5 to $-2.0 \mathrm{Wm}^{-2}$ is assumed (Seinfeld and Pandis, 1998; Jacobson et al., 2000). Furthermore, atmospheric aerosols influence the climate indirectly by acting as cloud condensation nuclei (CCN) (Novakov and Penner, 1993; Seinfeld and Pandis, 1998). An increased emission of aerosols to the atmosphere generates a higher concentration of $\mathrm{CCN}$, which, in turn, provokes a higher concentration of droplets with smaller radii in clouds. The result is an increased reflection of solar radiation from these clouds back to space and hence a cooling effect. Furthermore, the cloud size and its lifetime may also increase 
(Seinfeld and Pandis, 1998). Responsible for the cloud condensation effect of atmospheric aerosols are mainly water-soluble organic substances and inorganic salts, especially sulfate (Novakov and Penner, 1993; Seinfeld and Pandis, 1998). The content of sulfate in atmospheric aerosols can reach $39 \%$ of all water-soluble species (Kiss et al., 2000). Sulfate is directly emitted or generated by oxidation of sulfur dioxide $\left(\mathrm{SO}_{2}\right)$, dimethyl sulfide and hydrogen sulfide (Brimblecombe, 1996). Dominant natural sources include weathering of rocks and soil, volatile biogenic sulfur emissions from land and oceans as well as volcanoes. Combined natural sources are estimated to release globally between $80-120 \times 10^{6} \mathrm{t}$ of $\mathrm{SO}_{2}$. In 1995 global anthropogenic $\mathrm{SO}_{2}$ emissions were estimated to $142 \times 10^{6} \mathrm{t}$ (UNEP, 2002). Around $175 \times 10^{6} \mathrm{t}$ of sulfate are transferred annually from the oceans to the continents (Brimblecombe, 1996).

A considerable effort has been undertaken to characterize the chemical composition of atmospheric aerosols. Currently, inorganic components are well studied. Many non-polar compounds of the water-insoluble fraction have also been characterized (Jacobson et al., 2000). However, little is known about polar and water-soluble organic compounds (WSOC), which account for 20 to $70 \%$ of the total organic carbon (Saxena and Hildemann, 1996; Facchini et al., 1999; Kiss et al., 2000; Krivacsy et al., 2001). Polycarboxylic acids or humic-like substances (HULIS) constitute around one quarter of the WSOC (Fuzzi et al., 2002) and have been mainly studied by spectroscopic methods such as NMR, UV/VIS and fluorescence spectroscopy (Zappoli et al., 1999; Fuzzi et al., 2001; Suzuki et al., 2001). Polycarboxylic acids were identified by high performance liquid chromatography (HPLC) in combination with UV/VIS detection (Fuzzi et al., 2002). A recent study identified polymeric compounds as a major part of atmospheric organic aerosols using laser desorption ionization mass spectrometry (Kalberer et al., 2004). Moreover, the average molecular weight of HULIS isolated from fine atmospheric aerosols was estimated (Kiss et al., 2003). Identification of single compounds was attempted by comparing MS/MS fragment spectra of model compounds with HULIS (Cappiello et al., 2003). Nevertheless, a much more detailed characterization by mass spectrometry is necessary for a better understanding of the chemical nature of HULIS.

This work had the aim to obtain more structural information of HULIS by electrospray ionization mass spectrometry in the negative ion mode (ESI(-)-MS). ESI provides soft ionization and little fragmentation of labile compounds. Substructures of HULIS should be investigated by further fragmentation. For this purpose an ion trap mass spectrometer and multiple mass spectrometry $\left(\mathrm{MS}^{\mathrm{n}}\right)$ were used in combination with size exclusion chromatography (SEC) to separate HULIS from inorganic salts and other WSOC. The combination of mass spectrometry and SEC should offer considerable advantages concerning isolation and detection of HULIS as well as its structural characterization compared to off-line methods of sample pretreatment. 


\section{Experimental}

\subsection{REFERENCE MATERIALS AND CHEMICALS}

Octyl sulfate (Fluka, Switzerland), 2-hydroxy-5-sulfobenzoic acid (Fluka, Switzerland), 2-hydroxy-5-nitrophenyl sulfate (Aldrich, Switzerland) and 5bromo-4-chloro-3-indolyl sulfate (Acros, Belgium) were used as model compounds and were of $\geq 95 \%$ quality. Humic acid (Aldrich, Switzerland, catalogue number H1,675-2) and nordic aquatic fulvic acid (International Humic Substances Society, IHSS, USA, catalogue number 1R105F) were used as reference. Ammonium sulfate was obtained from Fluka (Switzerland). Acetonitrile (Multisolvent, HPLC) was purchased from Scharlau (Spain), and water was processed by an Elgastat Maxima HPLC water purification unit (Elga Ltd., UK). $\mathrm{D}_{2} \mathrm{O}$ was purchased from Cambridge Isotope Laboratories Inc. (USA). Helium of $99.996 \%$ (Carbagas, Switzerland) and Nitrogen of $99.5 \%$ purity from a high-purity nitrogen generator (NM30L; Peak Scientific Instruments, UK) were used.

\subsection{SAMPLING AND SITES}

Exposed quartz fiber filters (diameter $150 \mathrm{~mm}$, QF 20, Schleicher \& Schuell, Germany) were provided by the Lufthygieneamt beider Basel (Office for air hygiene of both Basel, Switzerland). The quartz fiber filters were not pretreated. A DHA-80 high volume sampler (Digitel AG, Switzerland) was used at a flow rate of $30 \mathrm{~m}^{3} \mathrm{~h}^{-1}$. The sampling period was $24 \mathrm{~h}$. Particulate matter $\leq 10 \mu \mathrm{m}\left(\mathrm{PM}_{10}\right)$ was collected by corresponding impactor settings. Filters assigned as QF $53(16 \mathrm{mg}$ of $\left.\mathrm{PM}_{10}, 21.07 .2003\right)$, QF 48 (22 $\mathrm{mg}$ of $\left.\mathrm{PM}_{10}, 14.08 .2003\right)$, QF 46 (18 $\mathrm{mg}$ of $\left.\mathrm{PM}_{10}, 10.09 .2003\right)$ and $\mathrm{QF} 34\left(17 \mathrm{mg}\right.$ of $\left.\mathrm{PM}_{10}, 23.12 .2003\right)$ were exposed at Feldbergstrasse (City of Basel, Switzerland, $47^{\circ} 43^{\prime} \mathrm{N}, 7^{\circ} 35^{\prime} \mathrm{E}$ ). Filters QF 87 (9 mg of $\left.\mathrm{PM}_{10}, 28.01 .2003\right)$, QF 79 (25 mg of $\left.\mathrm{PM}_{10}, 17.04 .2003\right)$ and QF 74 (17 mg of $\mathrm{PM}_{10}, 11.05 .2003$ ) were exposed at Zürcherstrasse (City of Basel, Switzerland, $47^{\circ} 43^{\prime} \mathrm{N}, 7^{\circ} 35^{\prime} \mathrm{E}$ ). In addition, filters QF 92 (24.1 mg of $\left.\mathrm{PM}_{10}, 19.10 .2001\right)$, QF 117 (21.9 $\mathrm{mg}$ of $\left.\mathrm{PM}_{10}, 15.10 .2001\right)$ and $\mathrm{QF} 119$ (23.1 $\mathrm{mg}$ of $\left.\mathrm{PM}_{10}, 17.10 .2001\right)$ were sampled on a rural site close to the city of Basel (Laufen, Switzerland, $47^{\circ} 25^{\prime} \mathrm{N}$, $\left.7^{\circ} 30^{\prime} \mathrm{E}\right)$.

\subsection{SAMPLE PREPARATION}

Filters were cut into small pieces with a metallic pizza cutter before extraction. The pieces were transferred to a $100 \mathrm{ml}$ flask (Schott, Germany). $52 \mathrm{ml}$ of water $(0.3 \mathrm{ml}$ $\mathrm{cm}^{-2}$ ) were added and shaken overnight by a shaker. The resulting slurry of quartz fibers and water was filtered through a glass fiber filter (GF 55, Ø25 mm, Schleicher $\&$ Schuell, Germany, preheated at $300^{\circ} \mathrm{C}$ ) and an underlaid nitrocellulose membrane filter (NC 03, Ø25 mm, $0.025 \mu \mathrm{m}$ pore size, Schleicher \& Schuell, Germany, 
no pretreatment) using a filtration apparatus with a perforated PTFE coated strainer (Selectron-GV, Schleicher \& Schuell, Germany). The filtration apparatus and the filters were rinsed with water before filtration. After filtration the apparatus and the filters were washed with $10 \mathrm{ml}$ of water. The clear yellowish extract of totally $62 \mathrm{ml}$ was used for characterization by SEC-ESI(-)-MS ${ }^{\mathrm{n}}$ without further preparation. Extracts of QF 117 and QF 119 were combined, evaporated to dryness and re-dissolved in $\mathrm{D}_{2} \mathrm{O}$. Evaporation was performed at $40^{\circ} \mathrm{C}$ to avoid thermal decomposition. Blanks were taken of the filtration apparatus, of all filters and of the water. There were insignificant compound quantities compared to real samples.

\subsection{SIZE EXCLUSION CHROMATOGRAPHY}

A column of $250 \mathrm{~mm}$ length and $4 \mathrm{~mm}$ i.d. filled with BioBasic-18 $\left(\mathrm{C}_{18}\right.$ phase, $5 \mu \mathrm{m}$ particle size and $300 \AA$ pore size (Thermo Electron, USA) was used. Separation was performed isocratically with $30+70(\mathrm{v} / \mathrm{v})$ water/acetonitrile using a Rheos 2000 pump (Flux Instruments, Switzerland) at a flow rate of $250 \mu \mathrm{l} / \mathrm{min}$. The mobile phase was previously degassed with a HP 1050 series degasser unit (Hewlett Packard, USA). Samples were injected with a PAL autosampler (CTC Analytics, Switzerland) in the partial loop mode. The injected volume was $10 \mu \mathrm{l}$.

\subsection{MASS SPECTROMETRY}

An ion trap mass spectrometer (LCQ classic, ThermoFinnigan, USA) was employed in the ESI negative ion mode. The following parameters were applied: sheath gas flow (nitrogen) 60 arbitrary units (arb), auxiliary gas (nitrogen) 0 arb, spray voltage $4.5 \mathrm{kV}$, heated capillary temperature $230^{\circ} \mathrm{C}$, capillary voltage $-10.5 \mathrm{~V}$ and ion time maximum $500 \mathrm{~ms}$.

An ESI time-of-flight mass spectrometer (ESI-TOF) (LCT, Waters-Micromass, UK) was used in the negative ion mode for accurate mass measurements. The measurements were performed by flow injection (10 $\mu$ l loop) to $50+50(\mathrm{v} / \mathrm{v})$ water/acetonitrile at a flow rate of $200 \mu \mathrm{l} / \mathrm{min}$. The parameters were applied as follows: capillary voltage $3 \mathrm{kV}$, sample cone voltage $40 \mathrm{~V}$, and source temperature $80^{\circ} \mathrm{C}$, desolvation temperature $100^{\circ} \mathrm{C}$, nebulizer gas flow $901 \mathrm{~h}^{-1}$ and desolvation gas flow $470 \mathrm{l} \mathrm{h}^{-1}$. Phosphate and its dimer and trimer were used as lock masses. Mass accuracy of the ESI-TOF was $3 \mathrm{mDa}$ for the mass range $m / z \quad 100-300$.

\subsection{DATA TREATMENT}

SEC chromatograms usually present signal intensity versus elution volume. However, for practical reasons intensity was plotted against retention time in this work. The background in a $1 \mathrm{~min}$ time window between 1 to $5 \mathrm{~min}$ was subtracted from chromatograms obtained in the full scan mode with Xcalibur software (Thermo Electron, USA). 


\section{Results and Discussion}

\subsection{CHROMATOGRAPHIC SEPARATION}

A conventional semi-analytical aqueous SEC column (PL aquagel-OH 30, $7.5 \mathrm{~mm}$ diameter, $300 \mathrm{~mm}$ length) filled with a standard polymeric stationary phase (polymethacrylate/polyglycol gel, $8 \mu \mathrm{m}$ particle size, $100-100.000 \mathrm{Da}$ ) was used for first separations employing as mobile phase $80+20(\mathrm{v} / \mathrm{v})$ water/acetonitrile at a flow of $400 \mu \mathrm{l} / \mathrm{min}$. The same column has been used to separate fulvic and humic acids (These and Reemtsma, 2003). However, too long retention times were observed increasing the risk of irreversible adsorption. HULIS are very polar and thus hardly retained on $\mathrm{C}_{18}$-reversed phases. Therefore, a $\mathrm{C}_{18}$-phase with 300 A pore size was used to combine SEC effects of the large pores with the inertness of the surface.

Preseparation of HULIS by solid phase extraction (SPE) as described by Limbeck and Puxbaum (1999) and Varga et al. (2001) was not necessary. The partial separation by HPLC was sufficient if combined with the selectivity of multiple mass fragmentation. Furthermore, only masses being part of the mass signal pattern of HULIS were chosen for multiple fragmentation to decrease the risk of interferences. The mass signal pattern of HULIS showed more intense odd number masses with maxima every $14 \mathrm{u}$ within the mass range $m / z$ 150-400 (Figures 2B and C). They probably originate from different degrees of saturation and variable chain lengths of HULIS (Kiss et al., 2001; Capiello et al., 2003; Kiss et al., 2003; Kalberer et al., 2004). Moreover, the more intense odd number masses probably contained no nitrogen. Even number masses were less intense and may accommodate an odd number of nitrogen atoms.

The main part of the WSOC in the filter extracts eluted between ca. 5.5-12 min as shown in Figure 1A for sample QF 34. Inorganic ions such as sulfate were partly separated from WSOC (retention time window 5.2-7.7 min, see extracted ion chromatogram for $\mathrm{HSO}_{4}^{-}$in Figure 1B). A first fraction of WSOC eluted at 7.6 min together with inorganic sulfate. Figure $2 \mathrm{~A}$ shows that $\mathrm{HSO}_{4}^{-}(m / z$ 97) was base ion within this time window and that the mass signal pattern of HULIS was present at a relative intensity of 5\%. The main fraction of WSOC started to elute at $8 \mathrm{~min}$ immediately after inorganic sulfate (Figure 2B). The signal pattern of HULIS was characterized by masses between $m / z \quad 150-400$ and more intense odd than even mass signals as already described by Kiss et al., 2003 (see expanded range of Figure 2C).

\subsection{MASS SPECTROMETRIC DETECTION AND FRAGMENTATION}

The presence of mass $m / z$ in the full scan spectrum (Figure 2B) after the elution of inorganic $\mathrm{HSO}_{4}^{-}(\mathrm{m} / z$ 97 in Figure 2A) was first interpreted as the presence of an organic compound with the same mass. TOF experiments gave an exact mass of $m / z$ 96.9647. This allowed to exclude organic compounds such as $\mathrm{C}_{4} \mathrm{HO}_{3}, \mathrm{C}_{5} \mathrm{H}_{5} \mathrm{O}_{2}$ or $\mathrm{C}_{6} \mathrm{H}_{9} \mathrm{O}$. Only $\mathrm{H}_{2} \mathrm{PO}_{3}^{-}$and $\mathrm{HSO}_{4}^{-}$with the calculated monoisotopic masses of 

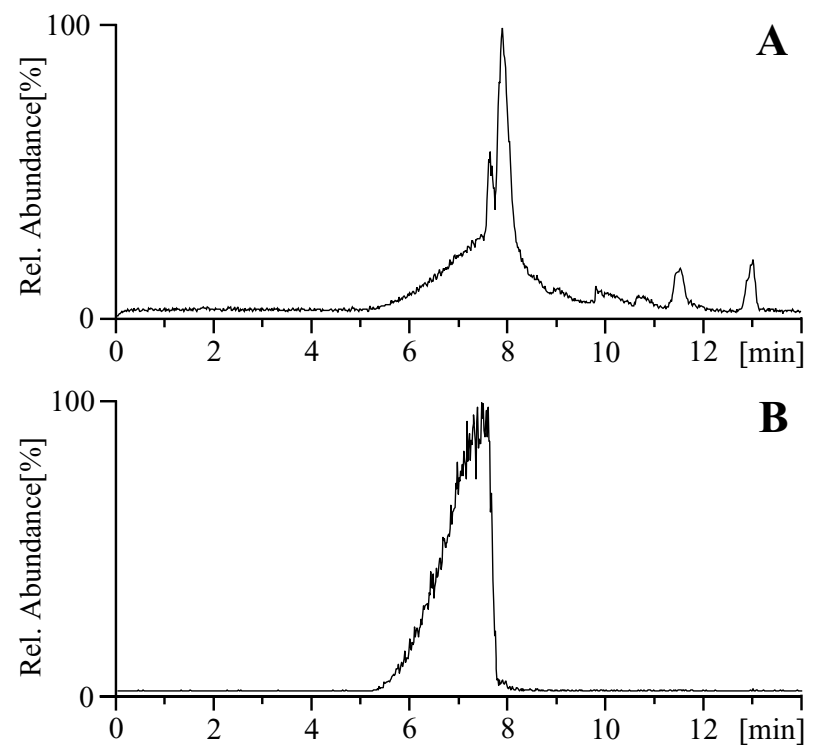

Figure 1. ESI(-) SEC chromatogram of filter extract QF 34. (A) Total ion chromatogram (TIC, $m / z 70-100,100 \%=1.5 \times 10^{8}$ counts). (B) Extracted ion chromatogram of $m / z 97$ $\left(100 \%=9.9 \times 10^{6}\right.$ counts $)$.

$96.9691 \mathrm{u}$ ( $45 \mathrm{ppm}$ off) and $96.9596 \mathrm{u}$ (53 ppm off) were valuable options. However, a clear distinction between $\mathrm{H}_{2} \mathrm{PO}_{3}^{-}$and $\mathrm{HSO}_{4}^{-}$was not possible at this stage.

Therefore, the mass change in $\mathrm{D}_{2} \mathrm{O}$ was evaluated using continuous-flowinjection with a syringe pump. This mode gave slightly different but well recognizable mass spectra compared to the SEC separation. Exchange of $\mathrm{H}$ by $\mathrm{D}$ should result in $m / z 97\left(\mathrm{H}_{2} \mathrm{PO}_{3}^{-}\right), 98\left(\mathrm{HDPO}_{3}^{-}\right)$and $99\left(\mathrm{D}_{2} \mathrm{PO}_{3}^{-}\right)$for $\mathrm{H}_{2} \mathrm{PO}_{3}^{-}$and was confirmed by ammonium phosphate with relative abundances of $100 \%$ for $\mathrm{HDPO}_{3}^{-}$, and $50 \%$ for $\mathrm{H}_{2} \mathrm{PO}_{3}^{-}$and $\mathrm{D}_{2} \mathrm{PO}_{3}^{-}$. However, the full scan spectrum (Figure $3 \mathrm{~A}$ ) showed only $m / z 98$ ( $\mathrm{DSO}_{4}^{-}$, base ion) and $m / z 97\left(\mathrm{HSO}_{4}^{-}, 90 \%\right)$. At $m / z 99$ only background noise was present. Therefore, the mass $m / z 97$ in the full scan spectra could be identified as $\mathrm{HSO}_{4}^{-}$.

The possible presence of sulfated HULIS as part of WSOC was investigated by fragmenting additionally odd number masses belonging to the mass signal pattern of HULIS. Filters QF 34, QF 117 and QF 119 were chosen in a first round. Candidates for further $\mathrm{MS}^{\mathrm{n}}$ experiments were selected from the SEC signal around 8 min within the mass range $m / z 220-320$ (Figure 2C). It contained the main part of the mass signal pattern of HULIS in the range $m / z 150-400$. Furthermore, the possibility of multiple charged masses was investigated. The zoom scan mode proved their absence in the mass signal pattern of the HULIS. The fragmentation of $m / z 299$ belonging to the mass distribution pattern of HULIS was representative for many other masses such as $m / z 229,265$ and 279. Therefore, more detailed investigations were carried out with this single mass. 

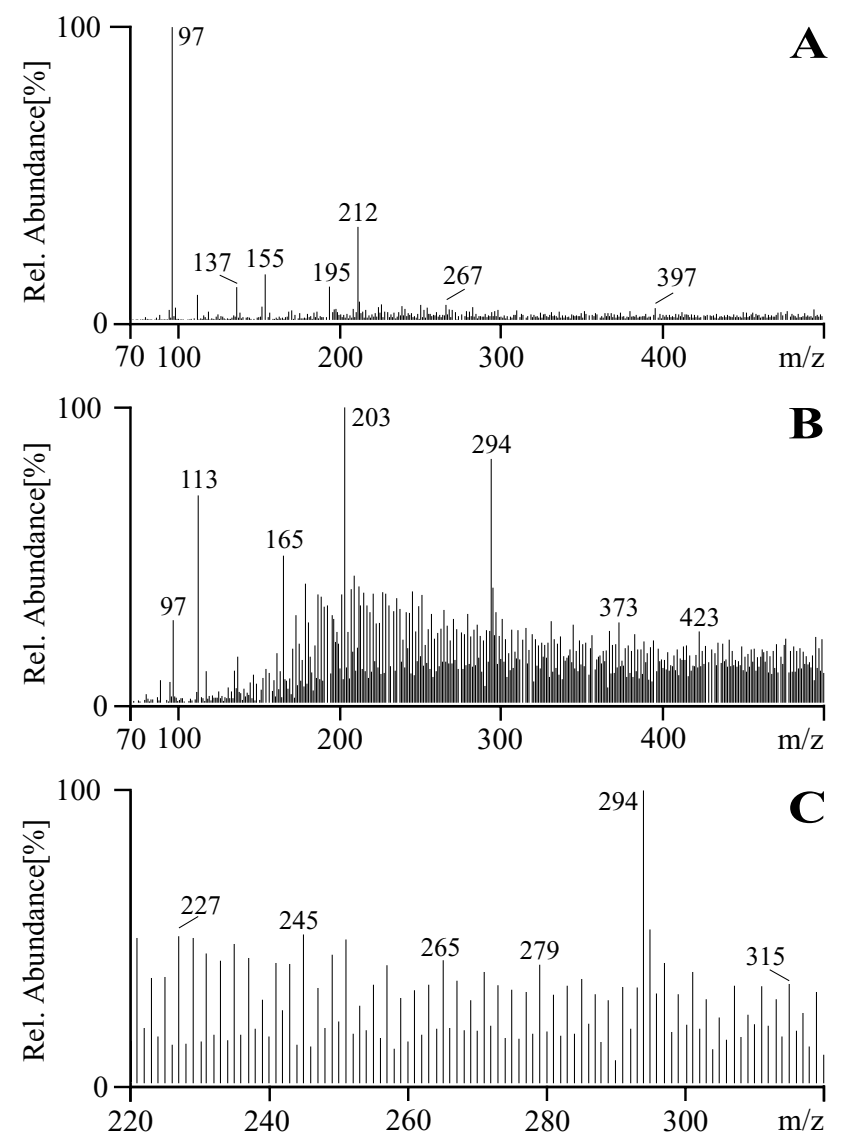

Figure 2. ESI(-) full scan spectra from filter extract QF 34 (see Figure 1). (A) Full scan spectrum $\left(m / z 70-500,100 \%=6.3 \times 10^{6} \mathrm{cps}\right)$ at $7.6 \mathrm{~min}$. (B) Full scan spectrum $(\mathrm{m} / z$ 70$\left.500,100 \%=1.1 \times 10^{6} \mathrm{cps}\right)$ at $8 \mathrm{~min}$. (C) Expanded full scan spectrum of $(\mathrm{B})(\mathrm{m} / \mathrm{z} 220-320$, $100 \%=9.1 \times 10^{5} \mathrm{cps}$ ) at $8 \mathrm{~min}$.

The $\mathrm{MS}^{2}$ spectrum of $m / z 299$ (Figure 4A) showed the typical fragmentation behavior of HULIS. Fragment $m / z 281$ corresponded to the loss of $\mathrm{OH}$ as water $(-18 \mathrm{u})$ and $m / z 255$ of $\mathrm{CO}_{2}$ from carboxyl groups. The fragment $\mathrm{m} / z 219$ was base ion and resulted from the cleavage of $80 \mathrm{u}\left(\mathrm{SO}_{3}\right)$. Further losses of $\mathrm{H}_{2} \mathrm{O}$ could be assigned to fragment ions of lower intensity (e.g. $m / z 237$ and 201). $\mathrm{HSO}_{4}^{-}(\mathrm{m} / z$ 97) had a relative intensity of ca. $70 \%$.

The fragments $m / z 281, m / z 255$ and $m / z 219$ were further dissociated and their $\mathrm{MS}^{3}$ spectra recorded (Figures 4(B-D)). Sufficient selectivity was obtained by isolating and fragmenting $m / z 299\left(\mathrm{MS}^{2}\right)$ as well as the subsequent isolation and fragmentation of its product ions $m / z 281, m / z 255$ and $m / z 219\left(\mathrm{MS}^{3}\right)$. Fragmentation of $m / z 281$ resulted in loss of $\mathrm{H}_{2} \mathrm{O}(\mathrm{m} / z 263), \mathrm{CO}_{2}(\mathrm{~m} / z$ 237) and again $80 \mathrm{u}(m / z 201)$. Mass $m / z 97\left(\mathrm{HSO}_{4}^{-}\right)$was present at a relative intensity of 

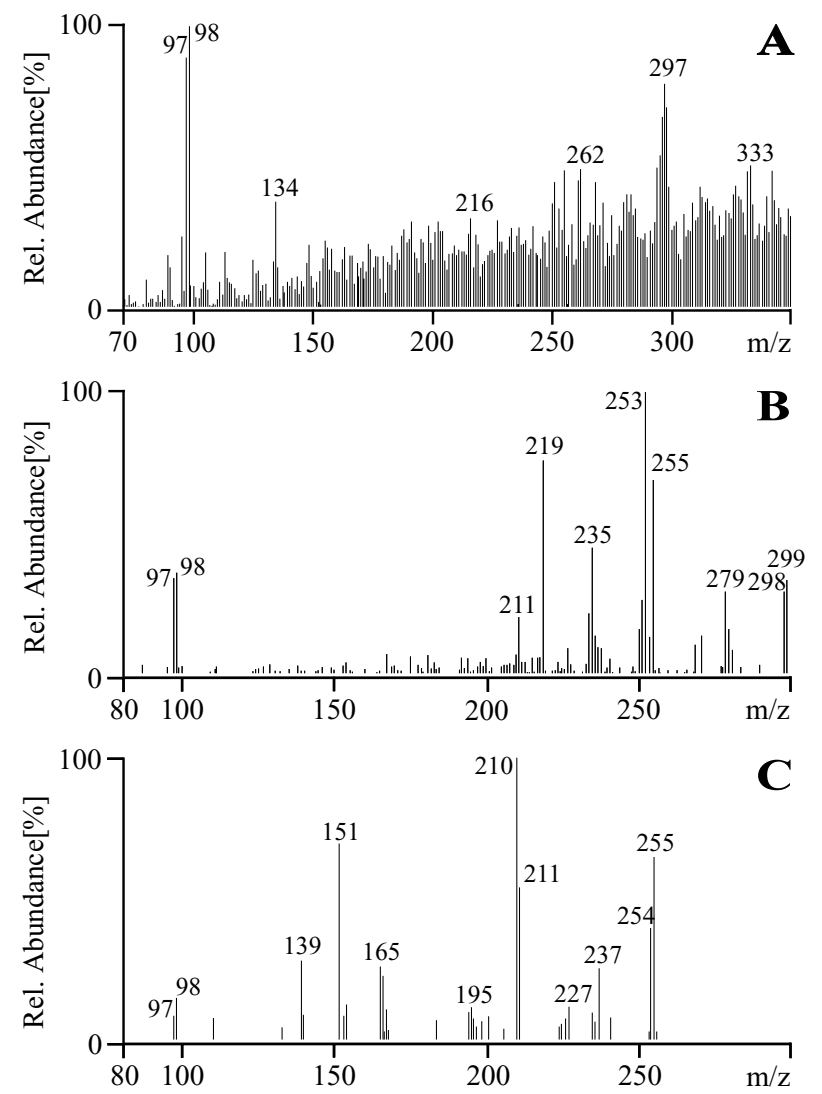

Figure 3. ESI(-) mass spectra recorded by continuous flow injection of WSOC in $\mathrm{D}_{2} \mathrm{O}$ solution of combined extracts (filter QF 117 and 119). (A) Full scan spectrum $(m / z, 70-350,100 \%=$ $7.1 \times 10^{5} \mathrm{cps}$ ). (B) $\mathrm{MS}^{2}$ fragment spectrum of $\mathrm{m} / z 299, \mathrm{~m} / z$ 80-300 (isolation width $1.5 \mathrm{u}$ indolyl sulfate, collision energy $\left.30 \%, 100 \%=3.0 \times 10^{4} \mathrm{cps}\right)$. (C) $\mathrm{MS}^{3}$ fragment spectrum of $m / z 299 \rightarrow m / z 255, m / z$ 80-300 (isolation width $2.0 \mathrm{u}$, collision energy $30 \%, 100 \%=$ $\left.1.3 \times 10^{4} \mathrm{cps}\right)$.

$30 \%$. The fragmentation behavior of $m / z 255$ was similar to $m / z 281$ yielding as main fragments $m / z 211\left(-\mathrm{CO}_{2}\right)$ and $m / z 237\left(-\mathrm{H}_{2} \mathrm{O}\right)$. Again, $m / z 175(-80 \mathrm{u})$ and $m / z 97\left(\mathrm{HSO}_{4}^{-}\right)$were observed. However, the fragmentation behavior of $\mathrm{m} / z$ 219 was significantly different. Only the losses of $\mathrm{H}_{2} \mathrm{O}\left(\mathrm{m} / z\right.$ 201) followed by $\mathrm{CO}_{2}$ $\left(\mathrm{m} / z\right.$ 157) and $\mathrm{CO}_{2}$ alone $(\mathrm{m} / z \mathrm{175})$ were observed. Cleavage of $80 \mathrm{u}$ and the $\mathrm{HSO}_{4}^{-}$ fragment at $m / z 97$ were missing. This suggested that loss of $80 \mathrm{u}$ and presence of $\mathrm{HSO}_{4}^{-}$are linked together. Moreover, $\mathrm{MS}^{2}$ and $\mathrm{MS}^{3}$ fragmentation experiments with $\mathrm{D}_{2} \mathrm{O}$ (Figures 3B and C) of $m / z 299$ (Figure 2C) formed both $m / z 97\left(\mathrm{HSO}_{4}^{-}\right.$) and $m / z 98\left(\mathrm{DSO}_{4}^{-}\right)$. This proved that fragmentation of HULIS also form $m / z 97$. The remaining filters showed a similar fragmentation behaviour and confirmed the findings independent of season and sampling site. 

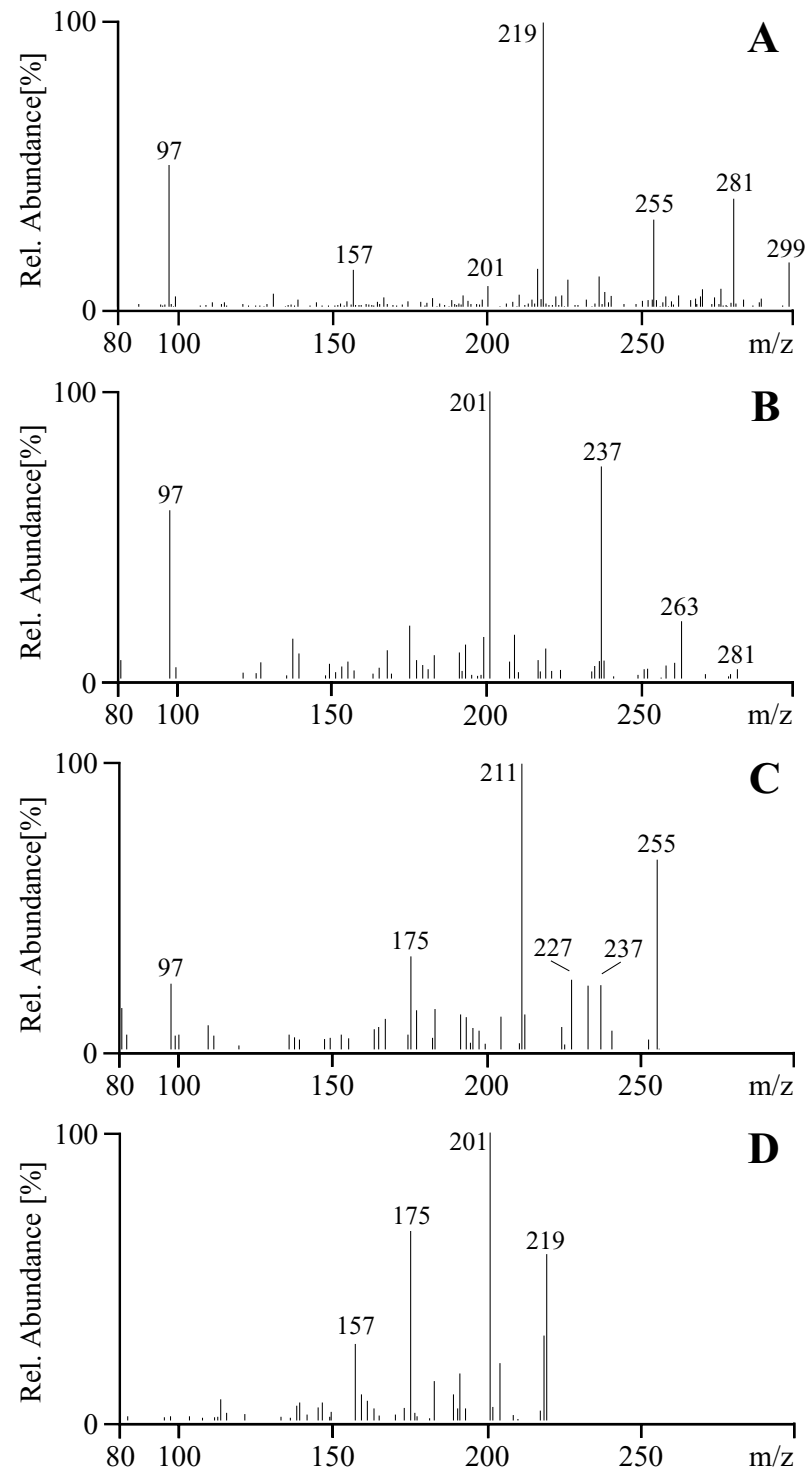

Figure 4. Fragment spectra from extract QF 92 (isolation width $1.5 \mathrm{u}$, collision energy $30 \%$ ). (A) $\mathrm{MS}^{2}$ fragment spectrum of $m / z$ 299, $\mathrm{m} / z$ 80-300 (100\% $\left.=5.6 \times 10^{4} \mathrm{cps}\right)$. (B) $\mathrm{MS}^{3}$ fragment spectrum of $\mathrm{m} / \mathrm{z} 299 \rightarrow \mathrm{m} / \mathrm{z} 281, \mathrm{~m} / \mathrm{z}$ 80-300 (100\% $\left.=3.2 \times 10^{3} \mathrm{cps}\right)$. (C) $\mathrm{MS}^{3}$ fragment spectrum of $m / z 299 \rightarrow m / z 255, m / z$ 80-300 (100\% $\left.=3.6 \times 10^{3} \mathrm{cps}\right)$. (D) $\mathrm{MS}^{3}$ fragment spectrum of $m / z 299 \rightarrow m / z 219, m / z$ 80-300 $\left(100 \%=4.3 \times 10^{3} \mathrm{cps}\right)$.

The MS ${ }^{2}$ spectra of $m / z 299$ formed from humic and fulvic acid extracts were studied to evaluate further the presence and formation of $m / z$ 97. They showed a very similar fragmentation as HULIS. However, the fragments $m / z 219$ and $m / z 97$ had a very low relative intensity of ca. $4 \%$ and $0.4 \%$, respectively. Moreover, fulvic 
Table I. Fragmentation behavior by ESI(-)-MS ${ }^{\mathrm{n}}$ of octyl sulfate (1), 2-hydroxy-5-sulfobenzoic acid (2), 2-hydroxy-5-nitrophenyl sulfate (3) and 5-bromo-4-chloro-3-indolyl sulfate (4)

\begin{tabular}{|c|c|c|}
\hline Compound & $\mathrm{MS}^{2}$ fragments & $\mathrm{MS}^{3}$ fragments \\
\hline (1) Octyl sulfate & $m / z 209 \rightarrow m / z 97\left(\mathrm{HSO}_{4}^{-}\right)$ & - \\
\hline (2) 2-Hydroxy-5- & $m / z 217 \rightarrow m / z 171(-46 \mathrm{u})$ & \\
\hline sulfobenzoic acid & $\rightarrow m / z 137(-80 \mathrm{u})$ & $\rightarrow m / z 93(-44 \mathrm{u})$ \\
\hline $\begin{array}{l}\text { (3) 2-Hydroxy-5- } \\
\text { nitrophenyl sulfate }\end{array}$ & $m / z 234 \rightarrow m / z 154\left(-80 \mathrm{u},-\mathrm{SO}_{3}\right)$ & $\rightarrow m / z 124(-30 \mathrm{u},-\mathrm{NO})$ \\
\hline $\begin{array}{l}\text { (4) 5-Bromo-4-chloro-3- } \\
\text { nindolyl sulfate }\end{array}$ & $m / z 324 \rightarrow m / z 244\left(-80 \mathrm{u},-\mathrm{SO}_{3}\right)$ & $\begin{array}{l}\rightarrow m / z 182\left(\mathrm{C}_{8} \mathrm{H}_{5} \mathrm{NO}_{2} \mathrm{Cl}\right) \\
\rightarrow m / z 79,81\left({ }^{79} \mathrm{Br},{ }^{81} \mathrm{Br}\right)\end{array}$ \\
\hline
\end{tabular}

acid and humic acid solutions were spiked with $50 \mathrm{mM}$ ammonium sulfate. No increase of the relative intensity of $\mathrm{m} / z 97$ was observed. This allowed to exclude $m / z 97$ as an artifact due to adduct formation with $\mathrm{HSO}_{4}^{-}$. All these experiments demonstrated, that $m / z$ 97 is a real fragment of HULIS and thus $\mathrm{HSO}_{4}^{-}$covalently bound.

\subsection{MODEL COMPOUNDS}

To confirm the observed fragmentation behavior and to link it further to sulfated HULIS, the fragmentation of model compounds (Table I) was investigated. MS ${ }^{2}$ fragmentation of octyl sulfate (1) gave the expected $m / z 97\left(\mathrm{HSO}_{4}^{-}\right)$fragment. Both 2-hydroxy-5-nitrophenyl sulfate (3) and 5-bromo-4-chloro-3-indolyl sulfate (4) lost $80 \mathrm{u}\left(\mathrm{SO}_{3}\right)$ and gave the fragments $m / z 234$ and $\mathrm{m} / z$ 324, respectively. The model compounds (1), (3) and (4) provided also an answer to the simultaneous appearance of $m / z 97\left(\mathrm{HSO}_{4}^{-}\right)$and $-80 \mathrm{u}\left(\mathrm{SO}_{3}\right)$ in the $\mathrm{MS}^{2}$ and $\mathrm{MS}^{3}$ spectra of HULIS. A loss of $80 \mathrm{u}\left(\mathrm{SO}_{3}\right)$ and $m / z 97\left(\mathrm{HSO}_{4}^{-}\right)$was observed, if sulfate was attached to a $\pi$-electron system containing electron withdrawing groups as in (3) and (4). A reason could be the stabilization effect of the $\pi$-electron system on the sulfate. The fragment $m / z 97\left(\mathrm{HSO}_{4}^{-}\right)$was present alone, if sulfate was attached to a purely aliphatic or aliphatic-behaving system, which was confirmed by (1). In this case no stabilization of the sulfate occurred. 2-hydroxy-5-sulfobenzoic acid (2) showed only a loss of $80 \mathrm{u}\left(\mathrm{SO}_{3}\right)$ as expected for sulfonated organic compounds.

Apparently, the appearance of simultaneously a loss of $80 \mathrm{u}$ and $\mathrm{m} / z$, 97 or of $\mathrm{m} / z$ 97 alone seem to be indicators for covalently bound sulfate. However, sulfonic acid groups as a further origin for $-80 \mathrm{u}\left(\mathrm{SO}_{3}\right)$ cannot be excluded. Furthermore, a combined presence of sulfonic acids losing $-80 \mathrm{u}$ and covalently bound sulfate yielding $m / z 97$ requires a humic-like molecule with a mass of $>177 \mathrm{u}$. The polycarboxylic nature of HULIS and the mass range of the studied HULIS $(m / z$ 150-400) makes an simultaneous occurrence of both groups in the same molecule not very much likely. 


\section{Conclusions}

The $\mathrm{MS}^{2}$ and $\mathrm{MS}^{3}$ fragment spectra provided enough evidence that $m / z 97$ is not an artifact. In addition, mass determination by TOF-MS excluded an organic structure, and fragmentation with $\mathrm{D}_{2} \mathrm{O}$-solution provided the proof that $m / z 97$ is $\mathrm{HSO}_{4}^{-}$. Altogether these facts make it very likely that $\mathrm{HSO}_{4}^{-}$is covalently bound to HULIS. However, since both sulfonation and sulfation of HULIS are possible in the atmosphere, $-80 \mathrm{u}\left(\mathrm{SO}_{3}\right)$ could not be clearly associated to sulfonated or sulfated HULIS. Both sulfated and sulfonated model compounds showed a loss of $-80 \mathrm{u}\left(\mathrm{SO}_{3}\right)$.

Moreover, it could be shown that sulfation of HULIS is likely, but this study did not allow to differentiate between a sulfation process of HULIS in the atmosphere, on the filter after collection or in the extract solution. Generally, sulfation occurs either by addition of sulfuric acid to alkenes or by esterification of an alcohol with sulfuric acid. The possibility of enzymatic sulfation is remote. Considering the chemical conditions for a sulfation (water, sulfate/sulfuric acid and HULIS), the possibility of sulfation in aerosol droplets in the atmosphere is real, but sulfation can also happen on the filter or in the extract solution.

Therefore, further investigations should be performed by sulfation of model compounds in a reaction chamber, which was not available for this study. HULIS should be generated in a smog chamber when $\mathrm{SO}_{2}$ or sulfate is present. Furthermore, the aging of HULIS should be studied, as there might be a correlation with the degree of sulfation. An estimation of the quantity of the sulfated HULIS fraction makes first sense after having confirmed its atmospheric origin. However, this is a difficult task, since the ionization yield in ESI $(-)$ is very structure dependent and ionization suppression by the remaining sample matrix is possible.

\section{Acknowledgments}

The authors thank M. Camenzind and M. Baumann from the Lufthygieneamt beider Basel (Switzerland) for the filters and M. Wind and F. Kuhn from Basilea Pharma (Switzerland) for the measurements on the TOF. We like to thank the Swiss National Science Foundation for the financial support under the project no. 2002.101473.01.

\section{References}

Brimblecombe, P., 1996: Air Composition \& Chemistry, Cambridge University Press, Cambridge. Cappiello, A., De Simoni, E., Fiorucci, C., Mangani, F., Palma, P., Trufelli, H., Decesari, S., Facchini, M. C., and Fuzzi, S., 2003: Molecular characterization of the water-soluble organic compounds in fogwater by ESI-MS/MS, Environ. Sci. Technol. 37, 1229-1240.

Facchini, M. C., Fuzzi, S., Zappoli, S., Andracchio, A., Gelencser, A., Kiss, G., Krivacsy, Z., Meszaros, E., Hansson, H.-C., Alsberg, T., and Zebühr, Y., 1999: Partitioning of the organic aerosol component between fog droplets and interstitial air, J. Geophys. Res. 104, 26821-26832. 
Fuzzi, S., Decesari, S., Facchini, M. C., Matta, E., and Mircea, M., 2001: A simplified model of the water soluble organic component of atmospheric aerosols, Geophys. Res. Lett. 28, 4079-4082.

Fuzzi, S., Facchini, M. C., Decesari, S., Matta, E., and Mircea, M., 2002: Soluble organic compounds in fog and cloud droplets: What have we learned over the past few years? Atmos. Environ. 64, 89-98.

Jacobson, M. C., Hansson, H.-C., Noone, K. J., and Charlson, R. J., 2000: Organic Atmospheric Aerosols: Review and state of the science, Review of Geophysics 38, 267-294.

Kalberer, M., Paulsen, D., Sax, M., Steinbacher, M., Dommen, J., Prevot, A. S. H., Fisseha, R., Weingartner, E., Frankevich, V., Zenobi, R., and Baltensperger, U., 2004: Identification of polymers as major components of atmospheric organic aerosols, Science 303, 1659-1662.

Kiss, G., Gelencser, A., Hoffer, A., Krivacsy, Z., Meszaros, E., Molnar, A., and Varga, B., 2000: Chemical characterisation of water soluble organic compounds in tropospheric fine aerosol, Proc. Conf. on Nucleation and Atmospheric Aerosols, 761-764.

Kiss, G., Varga, B., Gelencser, A., Krivacsy, Z., Molnar, A., Alsberg, T., Persson, L., Hansson, H.-C., and Facchini, M.C., 2001: Characterisation of polar organic compounds in fog water, Atmos. Environ. 35, 2193-2200.

Kiss, G., Tombácz, E., Varga, B., Alsberg, T., and Persson, L., 2003: Estimation of the average molecular weight of humic-like substances isolated from fine atmospheric aerosol, Atmos. Environ. 37, 3783-3794.

Krivacsy, Z., Hoffer, A., Sarvari, Z., Temesi, D., Baltensperger, U., Nyeki, S., Weingartner, E., Kleefeld, S., and Jennings, S. G., 2001: Role of organic and black carbon in the chemical composition of atmospheric aerosol at European background sites, Atmos. Environ. 35, 6231-6244.

Limbeck, A., and Puxbaum, H., 1999: Organic acids in continental background aerosols, Atmos. Environ. 33, 1847-1852.

Novakov, T., and Penner, J. E., 1993: Large contribution of organic aerosols to cloud-condensationnuclei concentrations, Nature 365, 823-826.

Saxena, P. and Hildemann, L. M., 1996: Water-soluble organics in atmospheric particles: A critical review of the literature and application of thermodynamics to identify candidate compounds, $J$. Atmos. Chem. 24, 57-109.

Seinfeld, J. H. and Pandis, S. N., 1998: Atmospheric Chemistry and Physics, Wiley-Interscience, New York.

Suzuki, Y., Kawakami, M., and Akasaka, K., 2001: ${ }^{1} \mathrm{H}$ NMR application for characterizing watersoluble organic compounds in urban atmospheric particles, Environ. Sci. Technol. 35, 2656-2664.

These, A. and Reemtsma, T., 2003: Limitations of electrospray ionization of fulvic and humic acids as visible from size exclusion chromatography with organic carbon and mass spectrometric detection, Anal. Chem. 75, 6275-6281.

UNEP, 2003: Global Environment Outlook 3 - GEO 2003, Earthscan Publication Ltd, London.

Varga, B., Kiss, G., Ganszky, I., Gelencser, A., and Krivacsy, Z., 2001: Isolation of water-soluble organic matter from atmospheric aerosol, Talanta 55, 561-572.

Zappoli, S., Andracchio, A., Fuzzi, S., Facchini, M. C., Gelencser, A., Kiss, G., Krivacsy, Z., Molnar, A., Meszaros, E., Hansson, H.-C., Rosman, K., and Zebühr, Y., 1999: Inorganic, organic and macromolecular components of fine aerosol in different areas of Europe in relation to their water solubility, Atmos. Environ. 33, 2733-2743. 